\title{
Study of Levonorgestrel IUCD In Management Of Dysfunctional Uterine Bleeding
}

\author{
Dr Thanmaye $B^{1}$, Dr B S Dhananjaya ${ }^{2}$ \\ ${ }^{1}$ Post Graduate, ${ }^{2}$ Professor \& Head, Department of Obstetrics and Gynecology, \\ Sri Siddhartha Medical College \& Research Centre, Agalakote, Tumakuru \\ DOI - 10.46319/RJMAHS.2019.v02i01.006
}

\section{Abstract}

Introduction: Dysfunctional uterine bleeding (DUB) is a common problem in women which causes discomfort and decreases the quality of life. About $10-15 \%$ of women experience episodes of DUB at some point of time during the reproductive years of their lives. Annually $5-19 \%$ of women seek medical care. It accounts for more than $25 \%$ of all hysterectomies. Many treatment options are available. Objectives: To study efficacy of levonorgestrel IUCD in terms of blood loss, endometrial thickness, hemoglobin concentration and to evaluate side effects in DUB. Materials and methods: 40 women presenting with dysfunctional uterine bleeding were treated with levonorgestrel IUCD. The primary outcome in the study was reduction in menstrual loss measured using pictorial blood loss assessment chart (PBAC) score, increase in blood hemoglobin levels, reduction in thickness of endometrium. The follow up was done at $3^{\text {rd }}$ and $6^{\text {th }}$ month. Results: This study shows reduction in PBAC scores with Levonorgestrel IUCD, hence reduction in blood loss. Increase in hemoglobin concentration with levonorgestrel IUCD and decrease in endometrial thickness with levonorgestrel IUCD. Conclusion: Levonorgestrel IUCD is efficacious and safe and is preferred in the treatment of DUB .

Keywords: Dysfunctional uterine bleeding, levonorgestrel IUCD, PBAC.

\section{Introduction}

DUB is a form of abnormal uterine bleeding with no recognizable pelvic pathology, pregnancy or generalized bleeding disorder. It mostly affects women in reproductive age. ${ }^{[1]}$ Sometime during the reproductive years, about $10-15 \%$ of women will have dysfunctional uterine bleeding. DUB is the common problem for many women which causes discomfort and also decreases the quality of life, by causing iron deficiency anaemia. ${ }^{[2]}$ $5-10 \%$ women in reproductive age group seek treatment for DUB annually because the quality of life is altered. It accounts for $6.2 \%$ of genitourinary disease and more than $25 \%$ of the hysterectomies. ${ }^{[3]}$

There are many different treatment modalities available for dysfunctional uterine bleeding such as medical therapy, minimally invasive techniques, surgical treatment. Medical therapies are hormonal and non hormonal. NSAID'S, ethamsylate and antifibrinolytics are found to be highly effective in nonhormonal drugs. The available hormonal agents include progestins, combined OCP's, danazol, GnRH agonists, latest SERMs, oestrogens, sometimes androgens, Levonorgestrel IUCD. RCOG recommends to begin with medical management before any surgical intervention. ${ }^{[3]}$

The first option to be tried always is medical management as it is less complicative, less morbidity, and economical. Many drugs are available for medical management. Each drug has its own advantages, disadvantages and side effects.

The minimally invasive technique for treatment of

Address for Correspondence:

Dr. Thanmaye B, Post Graduate, Dept. of Obstetrics and Gynecology, Sree Siddhartha Medical College and Research Centre, B H Road, Agalakote, Tumkur. E-mail:thanmave21@gmail.com 
menorrhagia is levonorgestrel intrauterine device. The Levonorgestrel ICUD contains 52mg levonorgestrel in reservoir with polydimethylsiloxane by which the release rate of hormone is controlled. Menstrual blood loss in women can be reduced by $75-95 \%$ by endometrial decidualization induced by progestins. Levonorgestrel IUCD is a good option for heavy menstrual bleeding in ovulatory women. Hysterectomy should be the final option in treatment of dysfunctional uterine bleeding, due to morbidity, mortality rate with the surgical techniques, economic burden and need for rest.

\section{Materials and methods:}

This longitudinal study included 40 patients in reproductive age group attending the outpatient department or admitted in-patients in obstetrics and gynecology department at Sri Siddhartha Medical College and Research Centre, Tumkur, during the period of November 2016 to April 2018. Reproductive age group women diagnosed with dysfunctional uterine bleeding were included. Women with pelvic pathologyfibroid uterus, endometriosis, PID, adenomyosis, chronic cervicitis and malignancies of uterus, ovary, cervix, vagina, complex endometrial hyperplasia with atypia and previous history of thrombosis, pregnancy and lactation, PCOS, platelet disorders, coagulopathy, Hypothyroidism, Chronic cervicitis, Jaundice, hepatic dysfunction, $\mathrm{Tb}$, renal impairment, Hypersensitivity to drug were excluded.

A detailed history, complete physical examination, routine investigations like hemoglobin, bleeding time, clotting time, platelet, RBS, thyroid function tests, liver function test, transvaginal USG were done to all patients. A written consent from the women who are included in the study was taken with ethical clearance from institute. The recruitment of the participants to the study groups were done after explaining about the merits and demerits and levonorgestrel intra uterine contraceptive device was inserted. They were advised to attend four weekly or earlier if required to OPD for follow up. Blood hemoglobin levels and endometrial thickness (TVS) were measured in the begining, at 3 months and at 6 months.

A well designed questionnaire, recorded the subjective assessment of menstrual flow and dysmenorrhea and/ or any side effects of drugs, PBAC score was recorded.
The outcome measures included were:

1) Pre treatment and post treatment evaluation of blood loss during menstruation by PBAC scores .

2) Blood haemoglobin levels.

3) Endometrial thickness (Trans vaginal scan).

Descriptive statistical analysis was carried out in the study.

\section{Results:}

The mean age of study population in levonorgestrel IUCD group was $40.50 \pm 2.88$. Majority of women in levonorgestrel IUCD group were from urban locality $(62.5 \%)$. All 40 women in the group were multiparous. Table 1 shows statistics of age distribution, locality and parity of subjects in levonorgestrel IUCD group.

Table 1: Sociodemographic distribution

\begin{tabular}{lcc}
\hline \multicolumn{1}{c}{ Parameters } & & LNG IUCD \\
\hline Age (Mean \pm SD) & & $40.50 \pm 2.88$ \\
Locality & Urban & $25(62.5 \%)$ \\
& Rural & $15(37.5 \%)$ \\
Parity & Nulliparous & $0(0 \%)$ \\
& Multipara & $40(100 \%)$ \\
\hline
\end{tabular}

Table 2: PBAC score, hemoglobin concentration, endometrial thickness with levonorgestrel IUCD treatment.

\begin{tabular}{lccc}
\hline Parameters & $\begin{array}{c}\text { Before } \\
\text { treatment }\end{array}$ & $\begin{array}{c}\text { 3 months } \\
\text { treatment }\end{array}$ & $\begin{array}{c}\text { 6 months } \\
\text { treatment }\end{array}$ \\
\hline PBAC & $172.08 \pm 41.50$ & $11.76 \pm 22.72$ & $3.97 \pm 10.96$ \\
$\begin{array}{l}\text { Endometrial } \\
\text { thickness }\end{array}$ & $10.02 \pm 3.15$ & $6.99 \pm 1.04$ & $5.43 \pm 1.21$ \\
Hemoglobin & $9.78 \pm 1.29$ & $10.14 \pm 1.96$ & $10.64 \pm 1.99$ \\
\hline
\end{tabular}

$\mathrm{PBAC}=$ pictorial blood loss assessment chart, $\mathrm{LNG}=$ Levonorgestrel

Table 2 shows PBAC scores, endometrial thickness, haemoglobin concentration before treatment, 3 months and 6 months after treatment in levonorgestrel IUCD. PBAC scores were reduced with LNG IUCD and there was a reduction in thickness of the endometrium with LNG IUCD after 6 months. There was also an increase in the haemoglobin concentration with LNG IUCD after 6 months. 
Thanmaye, et al.: Study of levonorgestrel IUCD in management of...

Table 3: Outcome distribution of patients

\begin{tabular}{lc}
\hline \multicolumn{1}{c}{ Outcome } & LNG IUCD \\
\hline Amenorrhea & $32(80 \%)$ \\
Symptomatically improved & $4(10 \%)$ \\
Dropout & $3(7.5 \%)$ \\
Hysterectomy & $1(2.5 \%)$ \\
Total & $40(100 \%)$ \\
\hline
\end{tabular}

Out of 40 patients treated with LNG IUCD, 32 patients attained amenorrhea, 4 patients symptomatically improved, 3 patients lost to follow up, 1 patient had hysterectomy (Table 3 ).

\section{Discussion:}

Medical treatment is to be tried as first option therapeutically and if the results fail, one can resort to surgical management. Medical management for menorrhagia has to aim for relieving symptoms, to improve the quality life and to reduce the surgical risk. This study was done to evaluate the efficacy and safety of levonorgestrel IUCD in the treatment of dysfunctional uterine bleeding.

Patients were treated with levonorgestrel IUCD. Patients were followed up for 6 months. Pre and post treatment outcome measures studied were as follows.

- Pre treatment and post treatment assessment of blood loss during menstruation objectively by PBAC chart.

- Blood hemoglobin levels

- Endometrial thickness (transvaginal scan).

Out of 40 patients treated with levonorgestrel IUCD, 32 patients attained amenorrhea, 1 patient underwent hysterectomy, 4 patients symptomatically improved and 3 patients lost to follow up.

Amenorrhea in our study was defined as absence of menstrual bleeding for 3 consecutive cycles.

Symptomatically improved patients $=$ patients in whom cycles were 45-60 days but there was significant reduction in bleeding, reduction in PBAC score, reduction in endometrial thickness and increase in hemoglobin percentage.

In this study, the patients who are treated with levonorgestrel IUCD shows significant decrease in blood loss during menstruation which was assessed by decrease in PBAC score. The mean value in pretreatment menstrual blood loss was $172.08 \pm 41.50$ assessed by PBAC score reduced to $11.76 \pm 22.72$ at 3 months and $3.97 \pm 10.96$ at 6 months .The results in table-2 suggests that the increase in haemoglobin level after 6 months of treatment was $10.64 \pm 1.99$ when compared to the level of $9.78 \pm 1.29$ pretreatment. The rise in haemoglobin level after 6 months was significant. The mean value in endometrial thickness in the pretreatment group was $10.02 \pm 3.15$ and there was decrease in mean endometrial thickness at the end of 6 months $5.43 \pm 1.21$ of treatment with levonorgestrel IUCD. Shalini et al studied 40 patients with dysfunctional uterine bleeding and found a statistically significant increase in haemoglobin levels (9.84 to $10.06 \mathrm{~g} / \mathrm{dl}$ ) and fall in mean PBAC score of $199.45 \pm 30.23$ before treatment to $53.18 \pm 14.73$ after 6 months of treatment with levonorgestrel IUCD ${ }^{[4]}$

Taru $\mathrm{G}$ et al studied 70 women with levonorgestrel IUCD insertion for heavy menstrual bleeding which resulted in decrease in blood loss during menstruation to $79 \%$ after 6 months of insertion. Improvement in haemoglobin levels from 8.16 to $9.35 \pm 0.7 \mathrm{~g} \%$ by 6 months ${ }^{[5]}$ In our study, no major side effects were seen with levonorgestrel IUCD. Only 4 patients out of 40 treated with levonorgestrel IUCD had history of spotting per vagina.

We found levonorgestrel IUCD had brought significant reduction in PBAC score, decrease in endometrial thickness and increase in haemoglobin concentration after treatment for 6 months in patients with dysfunctional uterine bleeding.

\section{Conclusion:}

Heavy menstrual bleeding or dysfunctional uterine bleeding is a very common gynecological problem with wide and varied treatment options with their own merits and demerits. Most of the western guidelines recommend Levonorgestrel IUCD as first line of treatment. From our study we found Levonorgestrel IUCD is efficacious and safe. Levonorgestrel IUCD is costly but one time administration with few side effects like spotting per vagina and can be recommended for the treatment of dysfunctional uterine bleeding.

\section{References}

1. Debasmita M, Sumit P, Sima S, Abhijit H, Saroj M, Tapan M, Comparitive study of low dose oral contraceptive pill and ormeloxifene in the treatment of dysfunctional uterine bleeding, International Journal of Health \& 
Thanmaye, et al.: Study of levonorgestrel IUCD in management of...

Allied Sciences. 2014 Oct-Dec;Vol.3(4):225-231.

2. Tariq N, Ayub R, Jaffery T, Rahim F, Naseem F and Kamal M, Efficacy of Levonorgestrel Intrauterine System (LNG-IUS) for Abnormal Uterine Bleeding and Contraception, Journal of the College of Physicians and Surgeons Pakistan. 2011; Vol.21(4):210-213.

3. Masand D, Gupta S, Patel J, To Observe Effect of Ormeloxifene in Medical Management of Dysfunctional Uterine Bleeding, J of Evolution of Med and Dent.2015 Jan 12:Vol.4(4):587-597.
4. Shalini Vasudeva, Gunjan Malhotra, SK Gulati, YS Chandel. Mirena and nuvaring in management of dysfunctional uterine bleeding. International Journal of Contemporary Medical Research 2018;5(4):D5-D9.

5. Taru G, Nupur G, Sangeeta G, Pushpa B, Jyoti J, Sushma K.(2014) Levonorgestrel Intrauterine System (LNGIUS) in Menorrhagia: A Follow- Up Study, Open Journal of Obstetrics and Gynecology, 4,190-196. http://dx.doi.org/10.4236/ojog.2014.44032. 